\title{
MECHANICAL PROPERTIES OF DIRECTIONALLY SOLIDIFIED AI-Si EUTECTIC
}

Danny Gene Morrow

M. S. thesis

May 1977

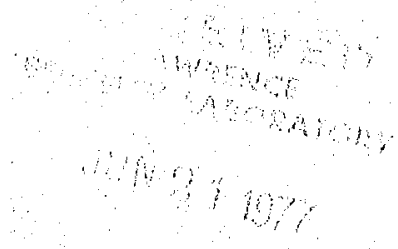

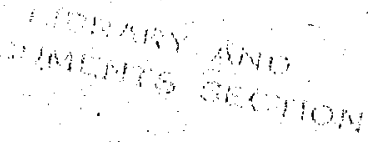

Prepared for the U. S. Energy Research and

Development Administration under Contract W-7405 ENG -48

\section{For Reference}

Not to be taken from this room

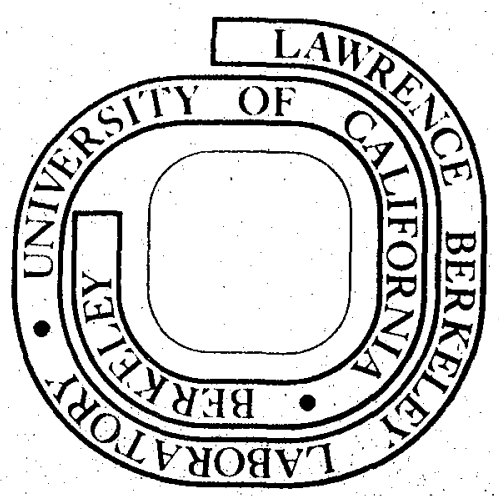



MECHANICAL PROPERTIES OF DIRECTIONAL,YY

SOLIDIFIED AI-Si EUTECTIC

\author{
BY \\ Danny Gene Morrow \\ Lawrence Berkeley Laboratory \\ Iniversity of California \\ Berkeley, California 94720
}

This work was done with support from the U.S. Energy Research and Development Administration. 
1 
ABSTRACT

The effect of directional solidification on the yield strength of the Al-asi eutectic alloy has been studied. Eutectic alloys (AI-12.7 Wt. $8 i$ ) were dinectionally frozen at growth rates, $R_{\theta}$ betwen 0.097 $\mathrm{cm} / \mathrm{h}$ and $47.0 \mathrm{~cm} / \mathrm{h}$ through a temperature gradient of about $80^{\circ} \mathrm{C} / \mathrm{cm}$. As found by Day and Hellawel1 (1), an oriented [001] Si fiber texture is obtained for rates less than $1.0 \mathrm{~cm} / \mathrm{hr}$, and at higher growth rates microstructures similar to the as-cast eutectic are found. At the lower growth rates, banded stnuctures altemating rich in Si and lean in Si were also observed. Tensile measurements indicated that the yield strength is independent of $\mathrm{R}$ at growth rates less than ca. $2.0 \mathrm{~cm} / \mathrm{h}$,

while at higher growth rates the strength increases linearly with $R^{1 / 4}$. Composite strengthening due to aligned si microstructure at low $R$ was not exibited due to the prefenential yielding within the banded struc tures. Yield strengths for higher growth rates are controlled by a precipitate spacing efsect.

1. Day, M. G. and Hellawe11, A. H, Pros. Royal S00, A305, 473-A91, (1971). 



\section{INPRODUCTION}

Directional solidification is both a useful means of controlling microstructures of materials in basic investigations and a potentially important industrial process for manufacture of in-situ composites. Applications of directional solidification techniques to eutectic alloys have been concentrated mainly in the class of eutectic alloys in which both phases have low entropies of fusion such as $\mathrm{Pb}-\mathrm{Sn}, \mathrm{Sn} \times \mathrm{Cd}, \mathrm{Sn}-\mathrm{Zn}$ and Al-zn (1) resulting in lamellar or rod-like morphologies.

A second class of eutectic alloys is that in which only one phase has a low entropy of fusion (e.g. Pbo-Bi, $\mathrm{Sn}-\mathrm{Bi}$ ). Among these alloys is the Al-Si eutectic which has a long history as the basis for industrial casting alloys (2). The phase diagram of the AI-Si system is shown in Fig. 1. As is characteristic of alloys in this class, when the alloy is rich in the low entropy phase (A1), the high entropy phase (Si) solidifies as primary crystals (1).

The purpose of this work has been to determine the effect of directional solidification on the yield strength of Al-Si eutectic and relate the yield strengths to the various microstructures present.

\section{BACKGROUND}

Suppression of independent growth of primary Si crystals is one of the prerequisites of a well-aligned in-situ composite. The following relationship (3) defines the conditions needed:

$$
G / R \geq \frac{M C_{S}\left(1-K_{0}\right)}{D K}
$$




$$
\text { whene: } \begin{aligned}
\mathbb{m} & =\text { liquidus temparature gradient } \\
K_{0} & =\mathrm{C}_{\mathrm{S}} / \mathrm{C}_{1}=\text { distribution coefficient } \\
\mathrm{C}_{\mathrm{S}} & =\text { composition of solid phase } \\
\mathrm{C}_{1} & =\text { composition of liquid phase } \\
\mathrm{D} & =\text { diffusion coefficient in liquid ahead } \\
& \text { of solid/iquid interface }
\end{aligned}
$$

Published information (3) an the effect of variations in growth rate and temperature gradient on this metal-non-metal eutectic identified three important regions (Fig. 2).

Region A: The very high $G / R$ ratio in this region produces large, inter connected, Eaceted Si crystals with a high incidence of \{111\} growth twins. These crystals project into the liquid ahead of the essentially planar and isothermal Al growth front (3).

Pegion B: In this region the silicon crystals assumed a variety of shapes and shared a nearly perfect [100] fiber cexture. As has been reported in other directional solidification experiments (4), the prefexred texture did not develog for the finst few centimeters of the ingot. The Si crystals grew in the form of high aspect ratio rods with side plates branching out radially. These side plates have been comared (3) to the secondary branches of dendrites, and were of two forms (Fig. 3): thin smooth \{100\} plates, or corrugated \{111\} plates with altemate sheets having (111) and (111) orientations. Throughout this region there were areas where large silican crystals were joined together in "instability bands" (3) "rich in silicon and lying nomal to the growth direction. The Si rich bands were interspersed with Al xich bands which 
have Si contents much lower than that of the eutectic composition. Region $\mathrm{C}$ : With an increase in $\mathrm{R}$ to greater than $\mathrm{ca} .1 .0 \mathrm{~cm} / \mathrm{h}$ the characteristic texture of Region B is no longer found: Si crystals are smaller in size and spaced closer together. An increase in the density of \{111\} Si growth twins was reported by Day and Hellawell (3) in this region. The microstructures characteristic of this region corresponded more closely to those found for typical cast alloys.

The aluminum phase in Regions $A_{B} B$, and $C$ shows no orientation relationship to the growth direction or to the silioon phase.

Previous Work: The previous investigation of the tensile properties of directionaIIy solidified Al-Si eutectic, by Steen and Hellawell (5) "was concemed only with Region C (growth rates from $3.6 \mathrm{~cm} / \mathrm{h}$ to $2880 \mathrm{~cm} / \mathrm{h}$ through temperature gradients from $110^{\circ} \mathrm{c} / \mathrm{cm}$ to $230^{\circ} \mathrm{c} / \mathrm{cm}$ ) using thin (4.5 mm dia) lang (25 m) solidification ingots. These authors concluded that cracks propagated along the faoes of Si "flakes". There was no attempt at yield strength measurements at yarious growth rates.

This author's work measured tensile properties of alloys solidified at both the higher growth rates previously studied, and also at growth rates below the transition point between the morphologies found in . Region $B$ and Region $C$. The intention of these tensile measurements was to relate trends in the tensile strength of the alloy to the microstructure effects resulting from directional solidification.

\section{EXPERTMENTAL}

Master ingots of the eutectic composition were prepared fxom 99.999 peroent purity aluminum and silioon. Solidification boats were fabricated 
From Norton \#24163 (AIumaum) combustion boats by cutting one end to Eit into a carbon chilling block (Fig. 4). Directional solidification was accomplished through the use of a quartz tube (aiameter $4.6 \mathrm{~cm}$ ) which passes through the center of a movable horizontal fumace (Fig. 5). The solidification prooess starts with the combustion boat containing approximately 100 grams of the master ingot placed within the quartz tube: which is evacuated and filled with argon gas to approximately two atmospheres. The furnace is then positioned around the boat and the sample ingot is heated in a molten state $\left(\mathrm{ca} .1000^{\circ} \mathrm{C}\right.$ ) for eight hours. Next a drive mechanism witharaws the fumace at the prescribed growth rate. $R$, which is taken to be the Ereezing rate. A copper cooling flange designed for the mouth of the furnace helps supply the ternoerature gradient necessary for solidification. Data of temperature versus furnace position was obtained using a chromel-alumel themocouple glucd into a slot machined in the botton of the solidification boat. From this temperature profile the tenperature gradient $G$ at the liquid solid interIace was detemined. Dinectionally solidified ingots were obtained for a series of growth rates ranging from $0.097 \mathrm{~cm} / \mathrm{h}$ to $47 \mathrm{~cm} / \mathrm{h}$ through a temperature gradient of approximately $80^{\circ} \mathrm{C} / \mathrm{cm}(\mathrm{Fig} \cdot 2)$. Cast microstructures were obtained using a water quench. The frozen ingots were characteristically $20 \mathrm{~cm}$ long with an average cross section of 1 on by $2 \mathrm{~cm}$. Because there are disturbed regions at the ends of directicnaliy solidified ingots (A), only the oenter section was used for both metallographic and tensile specimens. Prior to metallographic examination " transverse and Iongitudinal sections were polished and etched with Kellers reagent. 
Flat tensile test specimens were fabricated from the directionally solidified ingots as specified by ASrMM-E8-69 (Standard Methods of Tension Testing of Metaliic Materials). The long axis of the tensile specimen was parallel to the growth direction (Iongitudinal direction). Rectangular (subsize) specimens were used with a final thickness of approximately 0.165 an (gage length, 25mm; width, 6.25mm). These specimens were tested on an Instron two screw tensile machine, using a constant cross-head rate of $0.1 \mathrm{~cm} / \mathrm{hr}$. A non-averaging extensometer was attached to each specimen to recond the strain versus load. The yield strength values were then found using a $0.2 \%$ off-set method as described in ASTH-E8- 69 .

After tensile testing, the fracture faces were examined using a JOEL JSM-U3 Scanning Electron microscope. X- Xay Transmission Laue photographs were taken of specimens thinned to appraximately 0.031 cm using Ni filtered CuK radiation at $40 \mathrm{KV}$, and $20 \mathrm{ma}$. Specimen to photographic plate distance was 4 an and the exposure time averaged 60 minutes.

IV. RESULTS

Microstructures: Typical microstnctures obtained in this work are shown in Figs. 6a-6h. There are two significant features of these photomicnom graphs. At growth rates greater than about $1 \mathrm{~cm} / \mathrm{hr}$ (the higher growth rate regime) both the longitudinal (6a and $6 \mathrm{c}$ ) and the transverse (6b and 6d) micrographs show a similar arrangement of high-aspect ratio Si crystals (the dark phase) randonly arranged within the matrix. At growth rates less than I cm/hr (the Iower growth rate regime) the microstructure present showed a marked difference between the transverse (Figs. 6f and 6h) and Longitudinal (Figs. 6e and 6g) micrographs. These 
Latter photomicrographs suggest a composite-like structure composed of Si "rods" (with radial plates), aligned parallel to the growth direction within a matrix of aluminum.

Examples of a second type of microstructure found in the lower. growth rate region are illustrated in Fig. 7. The dark, Si-rich bands, compased of massive si crystals, are proninent at both of the growth rates shown. These bands are of irregular length: and there is a decrease in the spacing between bands with an increase in the growth xate from $0.097 \mathrm{~cm} / \mathrm{h}$ to $0.25 \mathrm{~cm} / \mathrm{h}$. Comparison between Fig. $7 \mathrm{a}$ and $7 \mathrm{~d}$ (both at the same magnification) clearly shows this decrease in spacing with growth rate, though the limited number of growth rates sampled restricts a more guantative analysis. At the growth rate of $0.25 \mathrm{~cm} / \mathrm{h}$ the $\mathrm{Si}$ depleted bands (white bands) are quite regular and extend across the entire width of the specimen.

X-ray Investigation: Typical Transmission Tave photographs are shown in Fig. 8. In the higher growth rate region there are conoontric spotty Debye rings for both the SI and Al phases (Figs. $8 \mathrm{a}$ and $8 \mathrm{~b}$ ). The Debye rings from the Si phase concentrate into arcs in the lower growth rate region, but the rings for the AI do not (Figs. $8 \mathrm{C}$ and 8d). The transition to the arc pattern is at the same growth region as that of the aligned silicon microstructure.

Tensile Tests: Sample stressustrain curves obtained for the higher growth rate regine are shown in Fig. 9. The yield strength as well as the strain to failure follow a general trend with $R$. Due to experimental difficulties with recoraing gortions of the strain data during tensile 
testing: a complete set of elastic modulus data could not be determined. Yield strength values derived from data such as from Fig. 9 are shown in Fig. 10. For reasons discussed later, an abscissa of $\mathrm{R}^{1 / 4}$ was chosen. There are two general regimes evident in these data which coincide rough Iy with those found previous ly in the photomicrographs. Below $R$ ca. $1.0 \mathrm{~cm} / \mathrm{hr}$ the yield strength appears to be independent of growth rate. However, for higher growth rates the yield strength curve is linear up to the highest rate used. The range of yield strengths in this regime fell between that of a chill cast specimen and the matrix component: essentially AI 1100.

SEM: Qualitative features of the fracture modes were investigated using a scanning electron microscope, Fig. 11. In the higher growth rate regime. Figs. $11 \mathrm{a}$ and $11 \mathrm{~b}$, the arrangement of the si crystals resulted in a randam combination of fracture faces at varying angles. There is also some evidenoe of plastic flow in the aluminum. At the lower growth rates, Figs. 11c, Ild, the Exacture faces show a high volume fraction of massive si crystals.

\section{DISCUSSION}

Microstructure: The photonicrographs shown in Fig. 6 corroborate the basic features of the work of Day and Hellawell (3). However, our investigation was concerned only with one temperature gradient $\left(\mathrm{ca} 80^{\circ} \mathrm{C} / \mathrm{cm}\right)$, so no comparison with Region A in Fig. 2 could be made. The effect of changes in the growth rate on the morphology and spacing of the silioon crystals is evident in the photomicrographs. Those taken of samoles in Region B verify the reported fiber texture and show the zigmag pattern 
Which results wen one of the $[111\}$ side plates is cut parallel to the fiber axis (Figs. $6 \mathrm{e}$ and $6 \mathrm{~g}$ ). The most striking change in morphology is the loss of texture when the growth rate changes fram 4.6 on/hr and $0.01 \mathrm{~cm} / \mathrm{h}$. Both the size and dispersion of the Si crystals is seen to gualitatively decrease as the $R$ increases in both the lower and higher growth rate negions.

Banded Microstructures: The "instability bands" reported by Day and Hellawell were quite prominent in the lower growth rate region. Whereas these authors characterized the instability bands as "interconnected. fiberous crystals": as shown in Fig. 7 , the bands found by this worker were made up of aggregates of laxge silicor particles. The Si-xich bands had a width of the order of 500, being comoosed of si crystals varying in size from 50y-100, in diameter (Figs. $7 b$ and 7c). The si depleted bands were narrowex (ca 20-50 ) and were made uo of a mach finer dispersion of Si particles (Figs. $7 \mathrm{c}$ and 7d). Electron beam microprobe investigations showed the volume fraction of Si in the Si-xick bands to be about 0.5 , dropping to less than about 0.02 in the 51 depleted bands.

Is mentioned earlier, there is a gualitative decrease in the distance between the si rich bands with an increase in $\mathrm{R}$ Irom $0.097 \mathrm{~cm} / \mathrm{h}$ to $0.25 \mathrm{~cm} / \mathrm{h}$, though the imegular nature of the bands and the limited data Erom two growth xates Iimits guantitative comparison to R. The banded microstructure was fand only in the central portions of the directionally solidified ingots. Comparison between Fig. 7 and the Lower growth rates of Iig. 6 indicate the texture evident in Figs.6e and $6 \mathrm{~g}$ is not found within the areas of banded microstructure. 
The Eactors governing the transition fron the aligned microstructure to the banded microstructure ane not totally understood at this point in our work. "he alloys characterized by Day and Hellatell (3) were directionally solidified at growth rates and temperature gradients similar to those used in this work, but the solidification apparatus was different. The vertical solidification apoaratus and maller diametex of the ingots grom by these workers may partially explain the difference between the bands found in their work and this work.

Texture: Verification of the reported $(2,4)(100]$ fiber testure of the \{111\} side plates characteristic of portions of Region B is supplied by

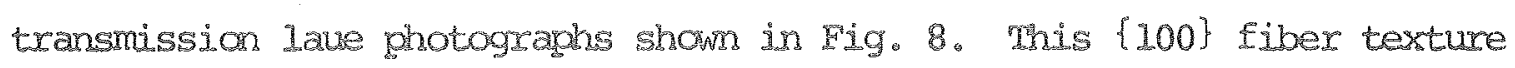
is illustrated in a stereographic projection shom in Fig. 12. Compaxisan between Figs. $10 \mathrm{c}$ and 10 with the steraographic projection verifies the relationship between the $\{100\}$ and the twinned $\{111\}$ side plates and the growth direction. The polycrgstalline rature of the aluninum results in the characteristic Debye rings negardess of the growth rate, while the silion rings disappear at the transition betwean Regions $B$ and $C$. The radial Lines in the photogravks are the result of the short wavelength rediation sti.11 present in the filtered cuKo x-yay beam.

The Effect of the Growth Rate an Inter-rod Spacing: Measurements on the ghotanicrographs were used to estimete a man inter-fiber spacing, $\lambda$, in Region C. The method used was to take linear traverses of a transverse section, count the nuber of intersections (with silicon micromerystals). divide by twice the width of the txansverse section and mutiply by the volume fraction of the Al phase. This procedure was repeated at least 
ten times on parallel lines and then an average was taken. A sumary of the results is presented in Fig. 13. Data obtained by Hellawe11 (3) for irregular microstructures in the Al-Si system are also plotted in Fig. 13. Only a qualitative comparison can be made, since their data for a different temperature gradient $\left(G=30^{\circ} \mathrm{c} / \mathrm{cm}\right)$. However, the data strongly suggest $\lambda^{2} R=$ constant in both instances.

The Effect of the Growth Rate on the Yield Strength

Higher Growth Rate Region: As finst observed by Pacz (2) "the cast eutectic Al-Si alloy fractures along the sharg faces of the randomly arranged Si crystals. As discussed earlier, the effect of growth rate on the spacing between si crgstals (Fig. 13) suggests the following relationship:

$$
\lambda^{2} R=\text { constant }
$$

Initial analysis of the yield strength values for specimens in this growth-rate region suggested a strang relationship between the si crystal spacing and the yield strength velues. Various graphical representations were attempted to determine the dependence of yield strength on growth rate, resulting in Figure 9. A Inear relationship between $R^{1 / 4}$ and yield strength is evident in the higher growth region of figune 9. Inis relationship can be represented as follows:

$$
\sigma=\text { constant }+C R^{1 / 4}
$$

Combining equations (1) and (2) results in a relationship between the yield strength and the inter-crystal particle spacing:

$$
0=\operatorname{constant}+0^{-1 / 2}
$$


Further analysis of the nature of the yielding in the higher growth-rate region is supplied by comparing Equation 3 to the much studied Hall-Petch relationship: relating the yield stress to grain size:

$$
\sigma=\sigma^{*}+k L^{-1 / 2}
$$

where

$$
\begin{aligned}
\sigma & =\text { Yield or Rupture Stress } \\
\sigma^{*} & =\text { Internal Stress } \\
K & =\text { Hall Petch Slope } \\
I & =\text { Grain Size of Interfiber Spacing, } \lambda .
\end{aligned}
$$

Although the mechanisms governing this relationship are not clear (4), the application of Equation 4 to two phase materials has been found valid when the difference in the modulus of elasticity of the two phases is great $(9,10)$ and when there is a good bond at the interface between the two phases (11).

Since the modulus of elasticity of $\mathrm{Si}$ is approximately three times that of A], The high aspect ratio Si cxystals act as a strong reinforcing phase. As seen in Fig. 9, there is considerable yielding at an almost constant stress before fracture, showing the strengthening effect of the randomly spaced Si particles. In the scanning micrographs (Fig. 11) of the fracture faces, it can be clearly seen that the fracture was predominantly along si cleavage faces.

Ii and chou (10) have discussed at length the flow stress-grain size relationship. The Hall-Petch relationship is obtained for a variety of models. They point-out that "Yielding is to take place when stress conoentration reaches the strength of the grain boundary." In our work 
there are two separate phases. The applicability of the Hall-Petch relationship in this case is also discussed by Ii and chou (10). Here yielding in aluminum starts before the stress reaches the fracture stress of the Si phase. Thus, although the fracture takes place in the silicon phase, the Hall-Petch relationship is applicable to the yielding in aluminum.

Lower Growth Rate Region: An initial imoetus for this work was the possible effects of the aligned si structures in the lower growth rate region on the yield strength. But, with the combination of the large Si crystals surrounded by a matrix of almost pure $A l$, the yielding is dominated by the stress concentrations arising within the Si-rich bands. The irregularly shaped Si crystals prematurely cleave resulting in a yield strength approaching that of pure aluminum. The nature of the yielding in this region does not allow a quantitative analysis of the strength of the aligned growth region.

In several metal-metal and non-metal-non-metal systems (17) directional solidification has produced composites (aligned microstrucm tures). A stress analysis of the aligned microstructures would consider the high-aspect Si crystals as reinforcing rods in a matrix of Al. The simplest model of this composite assumes that the bond between the two phases is capable of transferring stresses which develop due to the differing elasticities of the two phases.

For stresses within the elastic regime, the simple rule of mirtures describes the composite stress as a function of the volume fraction:

$$
{ }_{C}=\sigma_{R} V_{F}+\sigma_{M} V_{M}
$$


where,

$$
\begin{aligned}
& \sigma_{C}=\text { Stress in Composite } \\
& \sigma_{\mathrm{F}}=\text { Stress in Rod } \\
& \mathrm{G}_{\mathrm{M}}=\text { Stress in Matrix } \\
& V=\text { Volume Fraction }
\end{aligned}
$$

This relationship can be modified to take into account the orientation of the re-enforcing phase (8), the variability in length of the re-enforcing phase (16), and the strain hardening within the matrix.

The strengths of casting alloys similar to the alloy tested are dependent upon the re-enforcing offered by the silicon crystals (modified) dispersed in the Al matrix. Alignment of the si phase would increase the strength due to the cooperative effect of the two phases on the stress distribution. This added strergth would, of course, only be in a direction parallel to the direction of alignment of the Si "rods". The Al phase, acting as the composite matrix. would distribute loads between the Si "rods" by a shear mechanism.

The benefit of this metal-matrix comosite structure is not anly the added strength, but also the quality of the bond between the two phases. The major failing of most fabricated comoosite materials is their inability to efficiently transfer Ioads between the matrik and strengthening phases. The intexphase bond in directionaly solidisied alloys is characteristic of high integrity, improving both fatigue and high temperature characteristics. 
V. CONCLUSION:

Directional solidification of the eutectic Al-Si alloy, over a range of growth rates, was carried out: censile specimens fabricated, and longitudinal yield strengths measured. The yield strengths for growth rates greater than ca. $1.0 \mathrm{~cm} / \mathrm{hr}$ were dependent upon the spacings of the Si particles, following a Hall-Petch type relationship. The yield strengths of alloys solidified at rates lower than ca. $1.0 \mathrm{~cm} / \mathrm{hr}$ were dominated by preferential yielding within simich bands lying normal to the growth direction. Possible composite strengthening due to aligned Si microstructures in this growth regime was not realized due to this preferential yielding. 
PRFERENCES

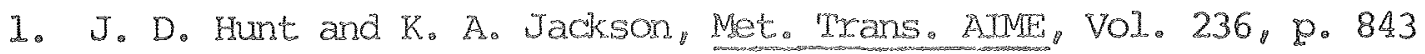
(1966)。

2. A. Pack, U. S. Patent 1,387,900 (1971)。

3. M. G. Day and A. H. Bellawe11, Proc. Royal Soc. A 305, pp. 473-491 (1971)。

4. G. A. Chadwick, Prog, Materials Science, 12, No. 2, 99 (1963)。

5. H. A. H. Steen and A. H. Hellawe11, Acta. Met, 20, 363 (1972).

6. B. D. Cullity, X-ray Diffraction, Addison-wesley, Co, (1956).

7. A. S. Yue, Met. Trans. ATME, 224, 1010 (1962)。

8. Fo D. Lenkey, $R$. Wo Hertaberg and Jo Ao Ford, Met. Trans. ATME, 233 334 (1965)。

9. H. Bibring, Conf. on In-Situ Composites (Proc.), $2,12-15$ (1972).

10. J. C. M. Ii and Y. T. Chou, Met. Mrans., 1, 1185 (1970).

11. Y. T. Chou, Can. J. of Phys, 45, 559 (1967)。

12. B. J. Shaw Acta Met, 15, 1169 (1967).

13. L. I. Broutman and R. H. Krock. Composite Materials, Vol. 5 Academic Press (1974).

14. W. D. Sylwestrowica, Bri1. Mag. 7, 1825 (1962).

15. K. R. Van Hom, Aluminum, ASM, 1967.

16. F. W. Crossman, Ao S. Zue, and A. E. Vidoz, Meto Trans. AIME, Vol. 245, pe. 397-106, (1969)。 


\section{FIGURE CAPTIONS}

Fig. I. Phase diagram of aluminum-silicon, Ref. 15.

Fig. 2. Temperature gradient $(G)$ and growth rate $(R)$ of test alloys.

Fig. 3. Tdealized drawing of si crystal, in lower growth region, showing crystallography of side plates and growth direction, Ref. 3.

Fig. 4. Carbon chilling block and solidification boat.

Fig. 5. Directional solidification apparatus.

Fig. 6a. Photomicrography of Iongitudinal section $(R=0.1 \mathrm{~cm} / \mathrm{hr}$ ) (magnification 100x)。

Fig. 60. Photomicrograph of transverse section $(R=0.1 \mathrm{~cm} / \mathrm{hr})$ (magnification 100x).

Fig. 6c. Photomicrograph of Iongitudinal section $(R=0.97 \mathrm{cn} / \mathrm{hr})$ (magnification 100x).

Fig. 6d. Photomicrograph of transverse section $(R=0.97 \mathrm{~cm} / \mathrm{hr})$ (magnification 100\%).

Fig. 6e. Photomicrograph of Iongitudinal section $(R=2.6 \mathrm{cu} / \mathrm{hr})$ (magnification 100x).

Fig. 6f. Photonicrograph of transterse section $(R=4.6 \mathrm{~cm} / \mathrm{hr})$ (magnification 100x).

Fig. 6g. Photomicrograph of longitudinal section $(R=23.0 \mathrm{~cm} / \mathrm{hr})$ (magnification 100ss)。

Fig. 6h. Photomicrograph of transverse section $(R=23.0 \mathrm{~cm} / \mathrm{hr}$ ) (magnification 100\%).

Fig. 7a. Photomicrograph of instability bands lying normal to growth direction $(R=0.1 \mathrm{~cm} / \mathrm{hr})$.

Fig. 7b. Photomicrograph showing large si crystals within instability 
barnds $(R=0.1 \mathrm{cop} / \mathrm{hos})$.

ig. 7c. Photonicrogroph of instability bands in low growth rate region $(R=0.25 \mathrm{cu} / \mathrm{hr})$.

Fig. 7d. Detail of Kig. 6c showing raxious types of banding.

Fig. 8a. Transmission Lave Rhotogran (R=23.0 cm/hx).

Fig. 8b. Transmission Lave Photograph Ldentifying Debye Rings $R=2.4(\mathrm{~s})$

Fig. 8C. Transmission Laue Ehotograph $(R=0.25 \mathrm{~cm} / \mathrm{hr})$.

Fig. 2d. Transmission Iaue Photograph $(R=0.97 \mathrm{~cm} / \mathrm{hr})$.

Fig. 9. Stress/strain curves fox directonally solidified alloys.

Fig. 10. Variation of yield strangth with $R^{1 / 2}$.

Fig. 1la. SEM photograph $(R=4.6 \mathrm{~cm} / \mathrm{r})$ magnification $300 \%$.

Fig. 11b. SEM photograph $(K=23.0 \mathrm{~cm} / \mathrm{m})$ magnification $300 \mathrm{x}$

Fig. 2lc. SEM photograph $(\mathrm{R}=0.1 \mathrm{~cm} / \mathrm{h} x)$ magnie

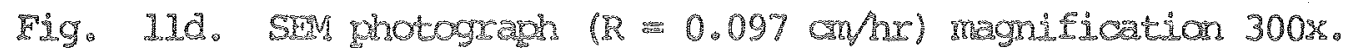

Fig. 12. Stexegraphic projection of [100] testure of $\{11\}$ side plates.

Fig. 13. Rejationship betwees intex-Lamella spacing and growth rate. 


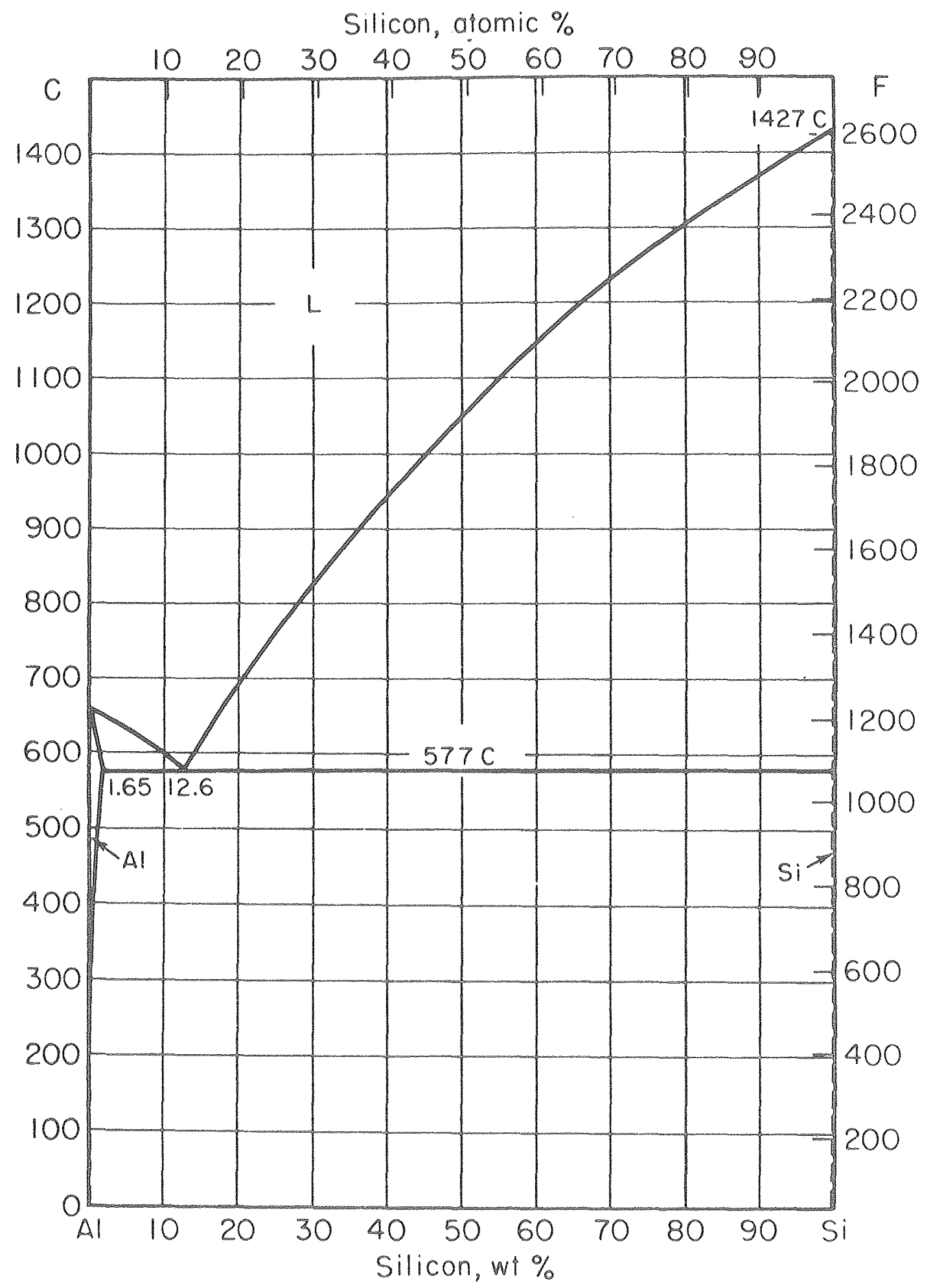

Fig. I

XBL 7512-10076 
$00+3+7,+0,400$

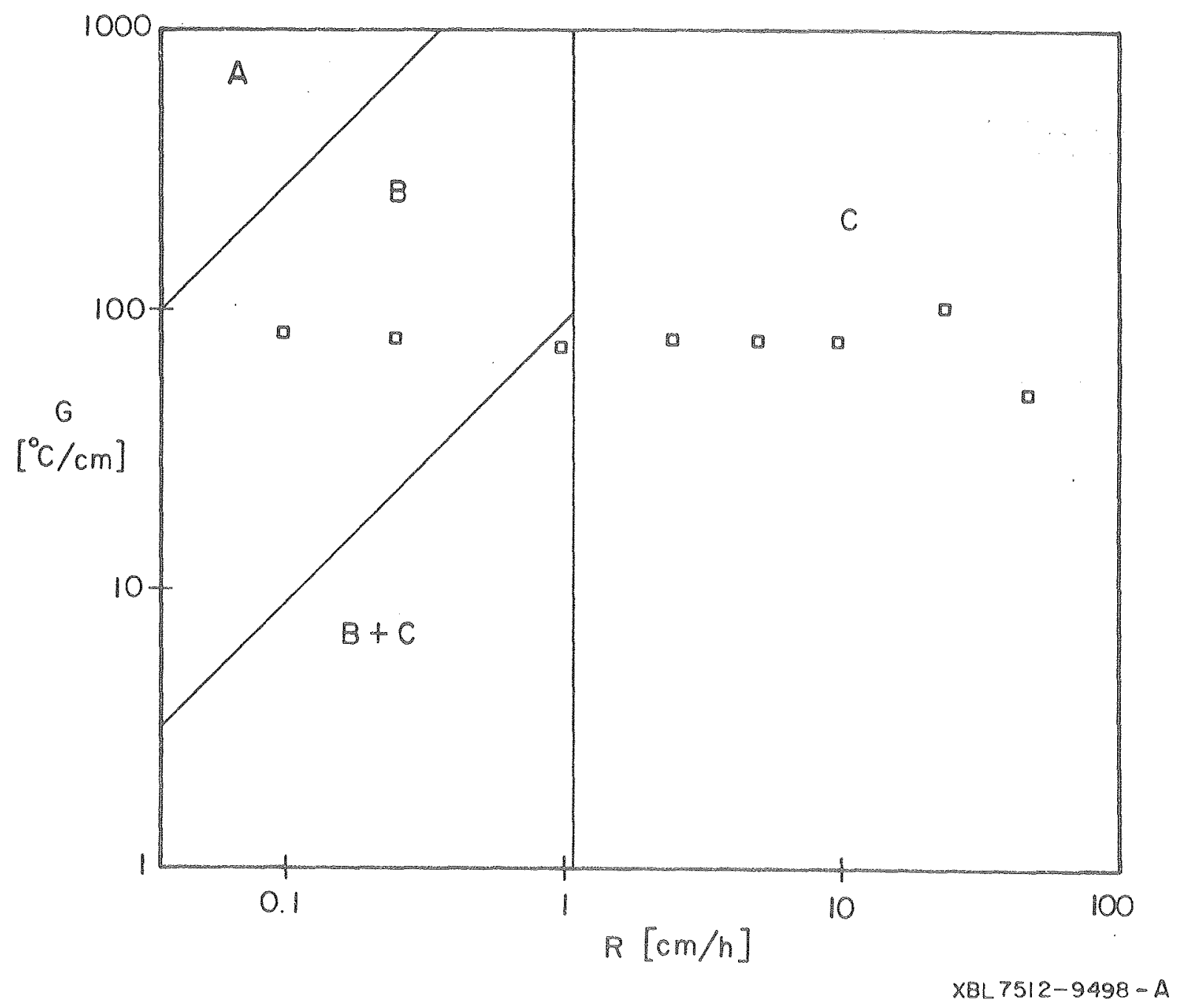

Fig. 2 


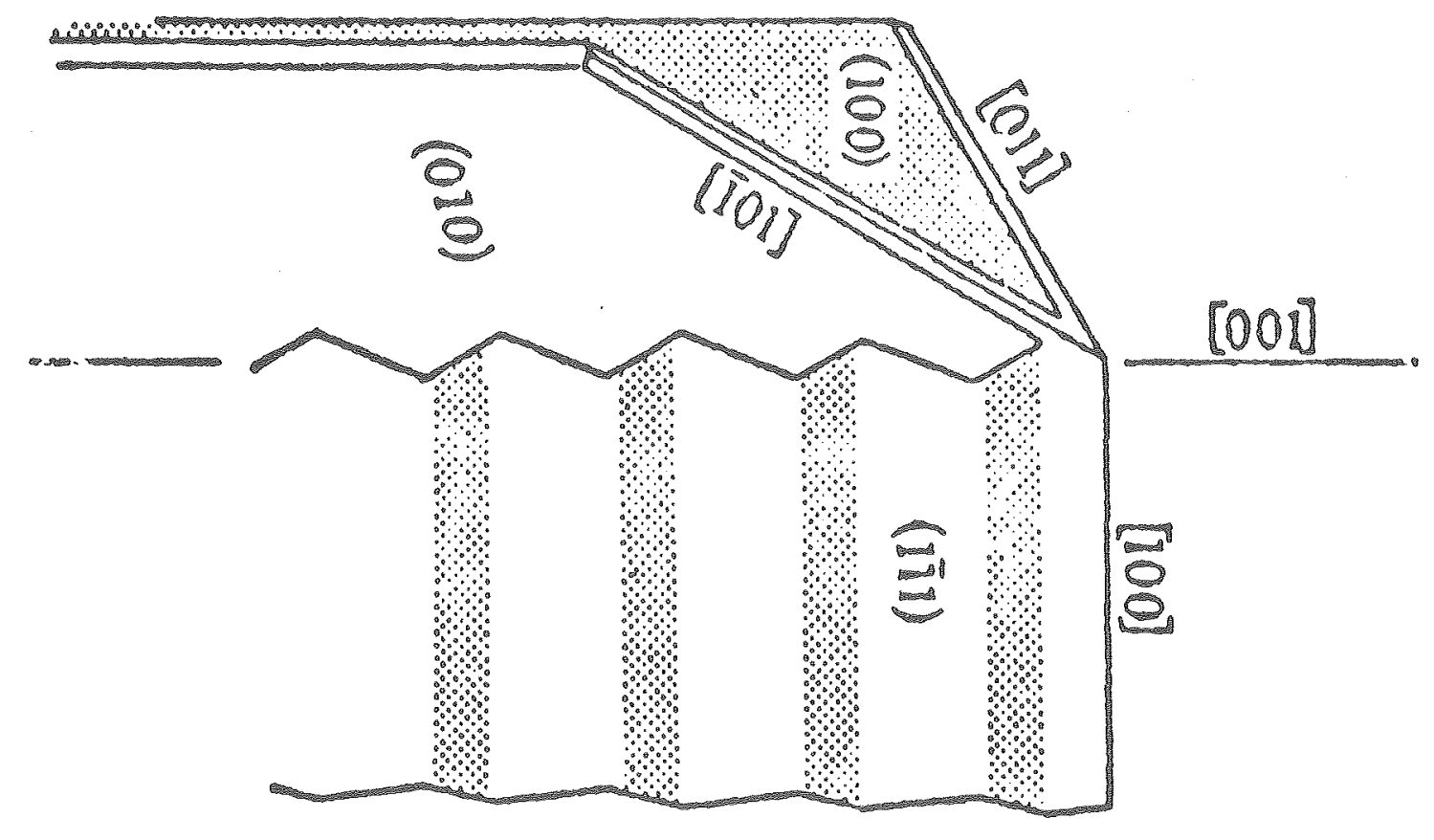

Eig. 3

XBL 763.754 


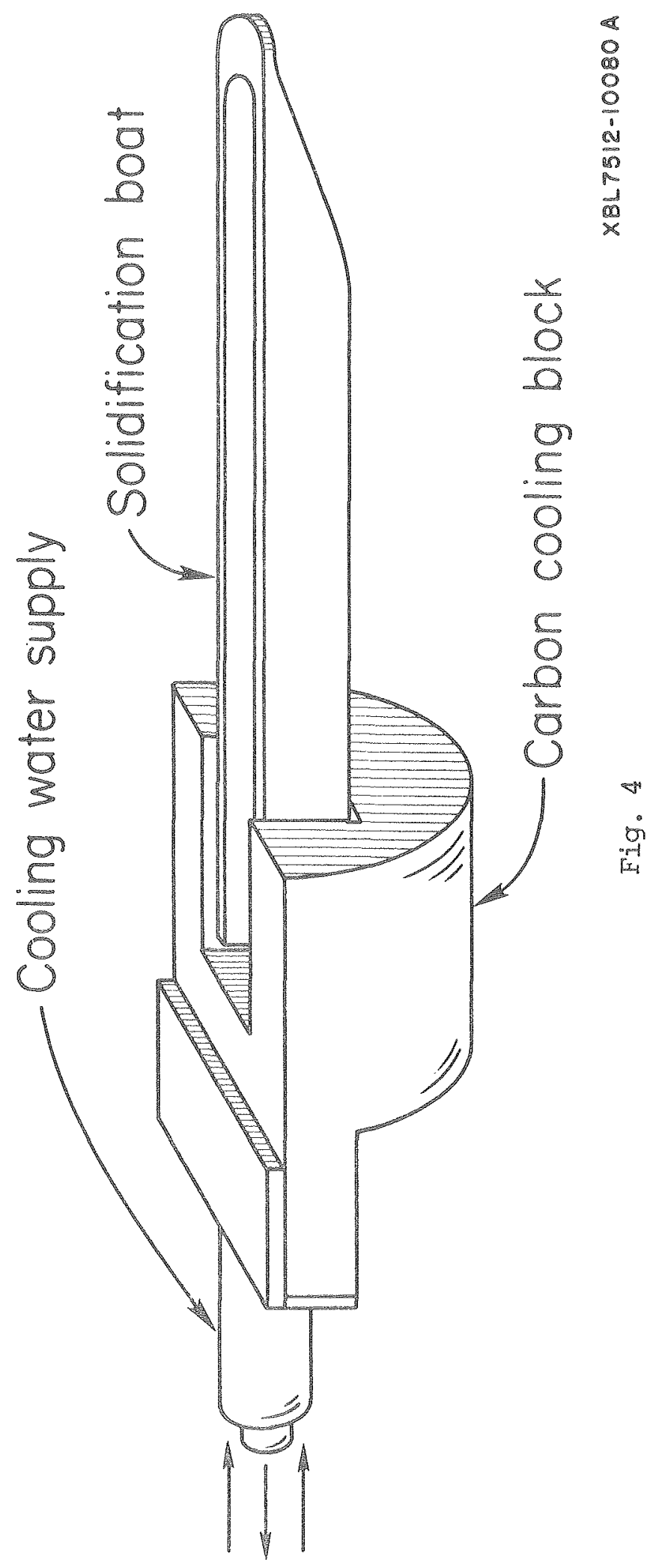




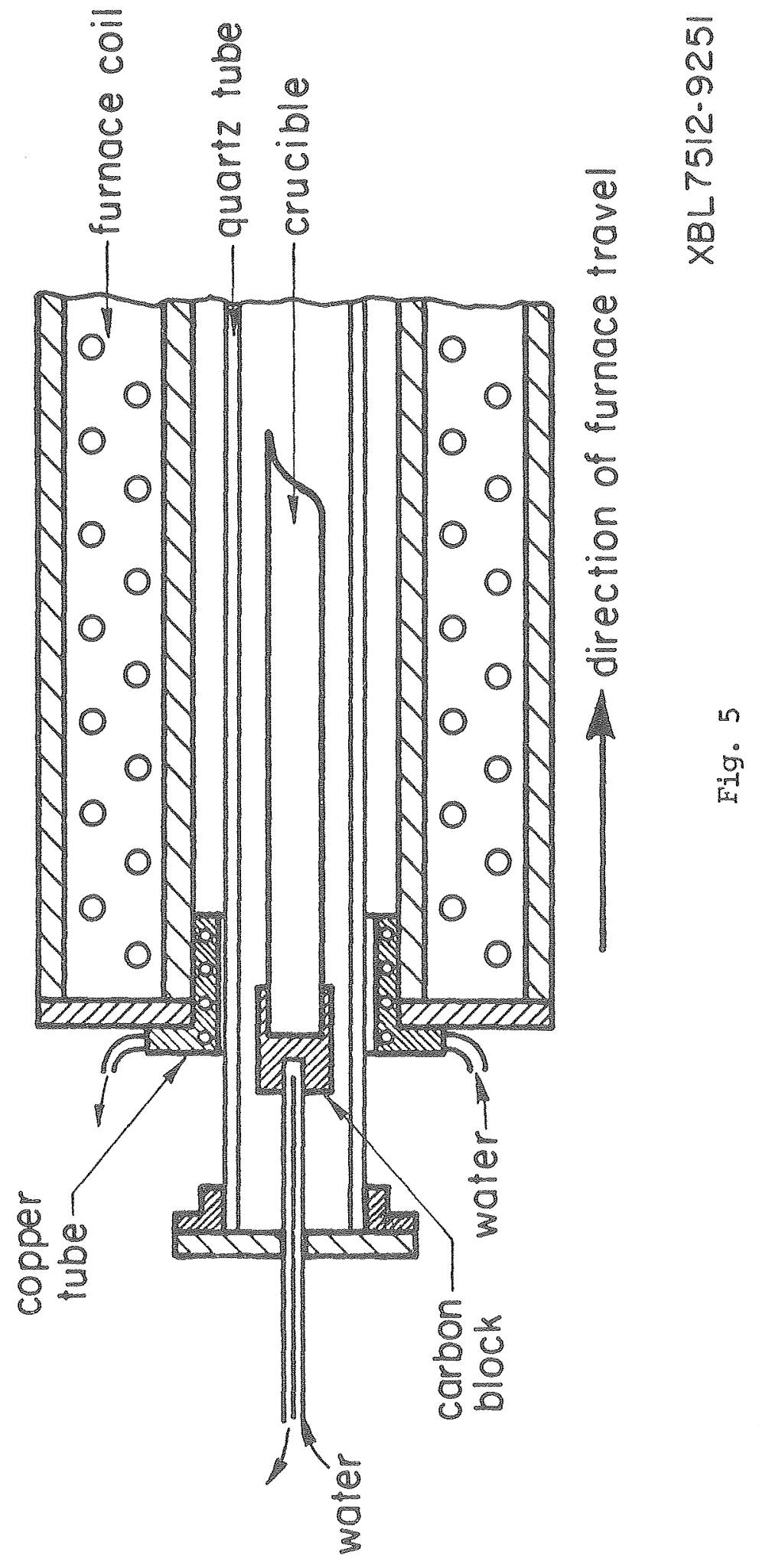




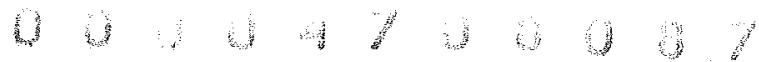

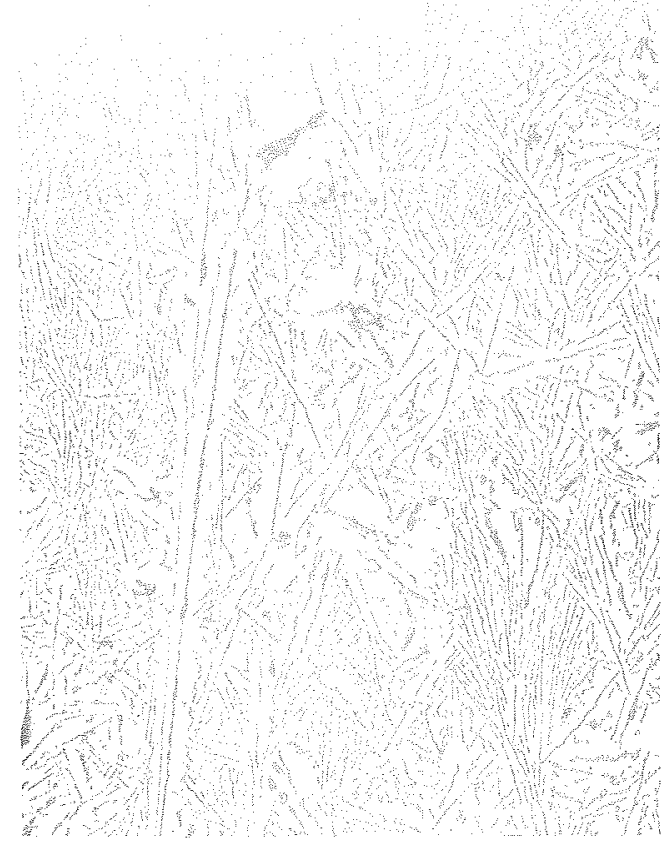

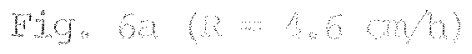

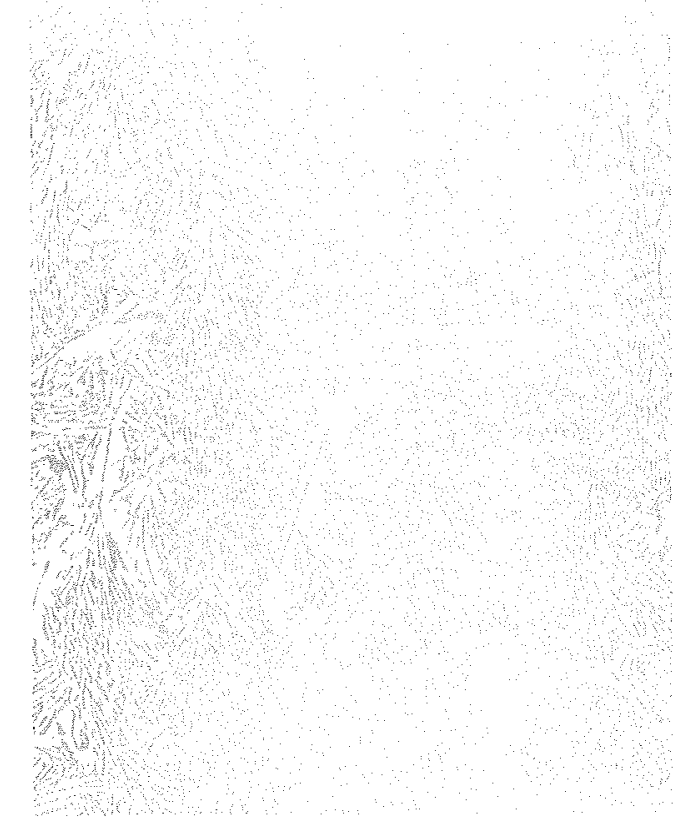

its?

Growh Direstios
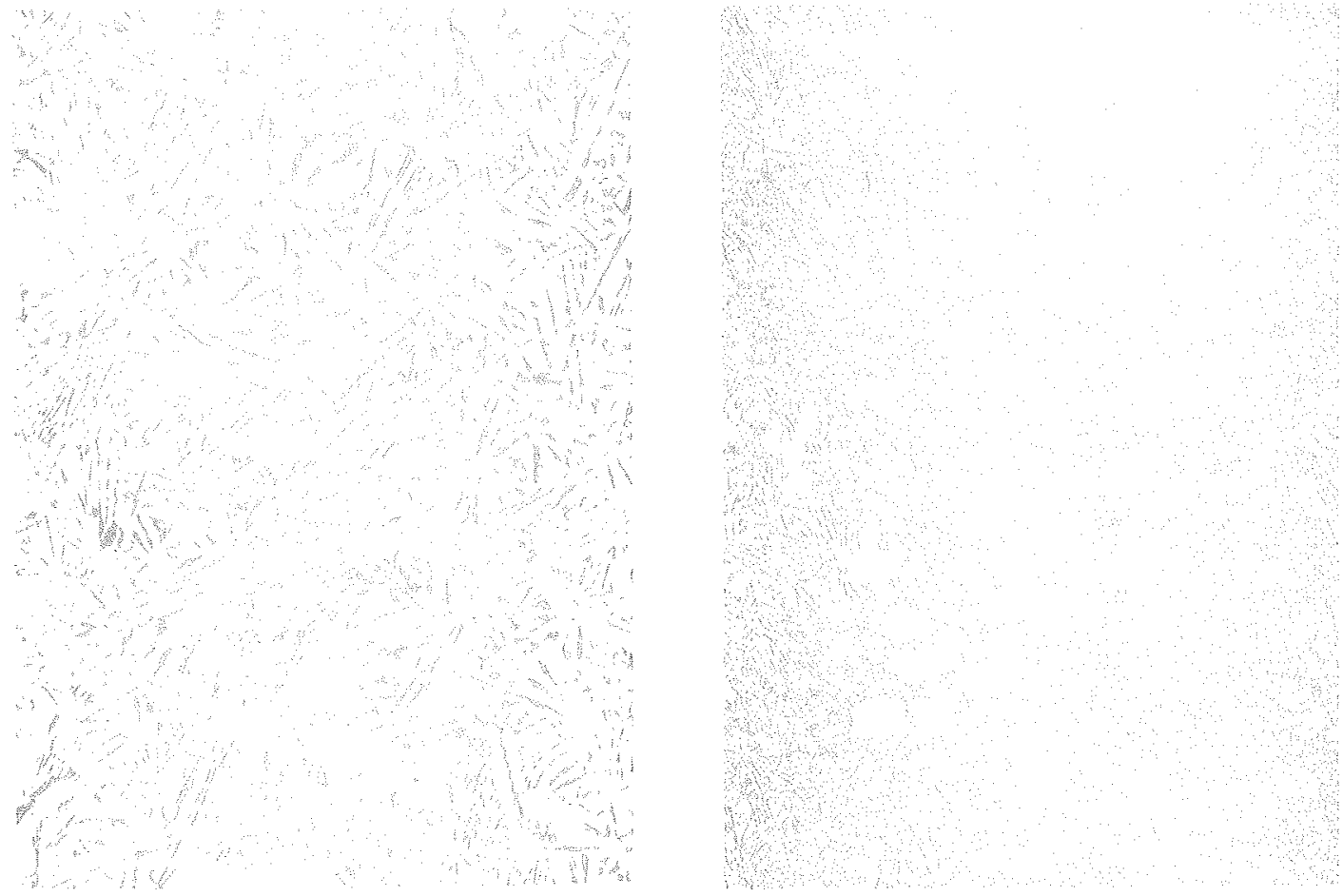

He. 0 


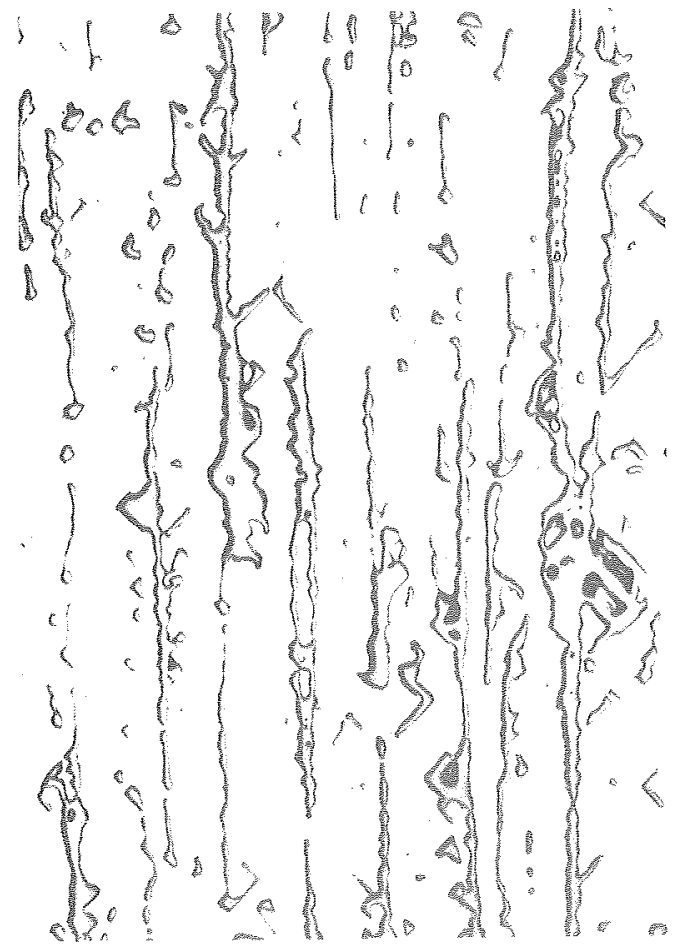

$\lg \cdot 6 \mathrm{e}$

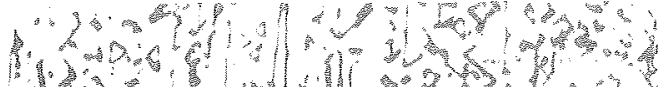
B.

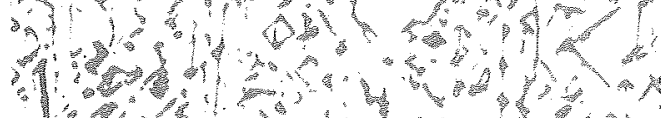
a

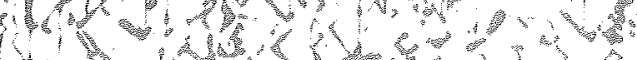

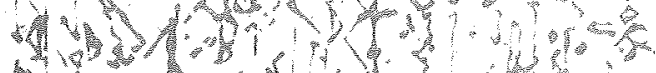

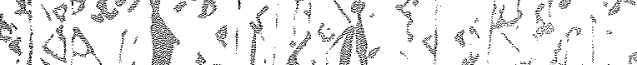

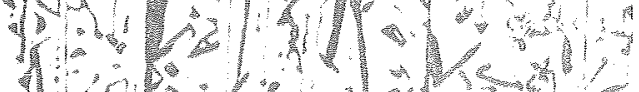
IIt?

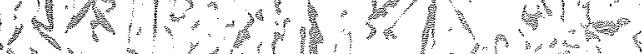

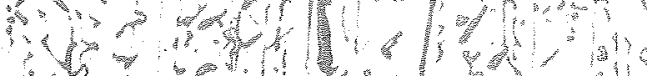

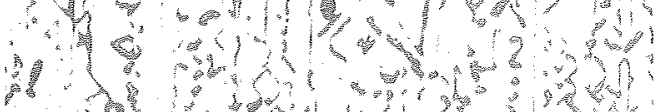
5 - 1 B n

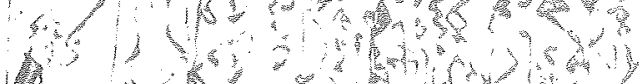
W. , n 篦品

Fig. 69

Direction $(\mathrm{m}=0.25 \mathrm{~cm} / \mathrm{h})$

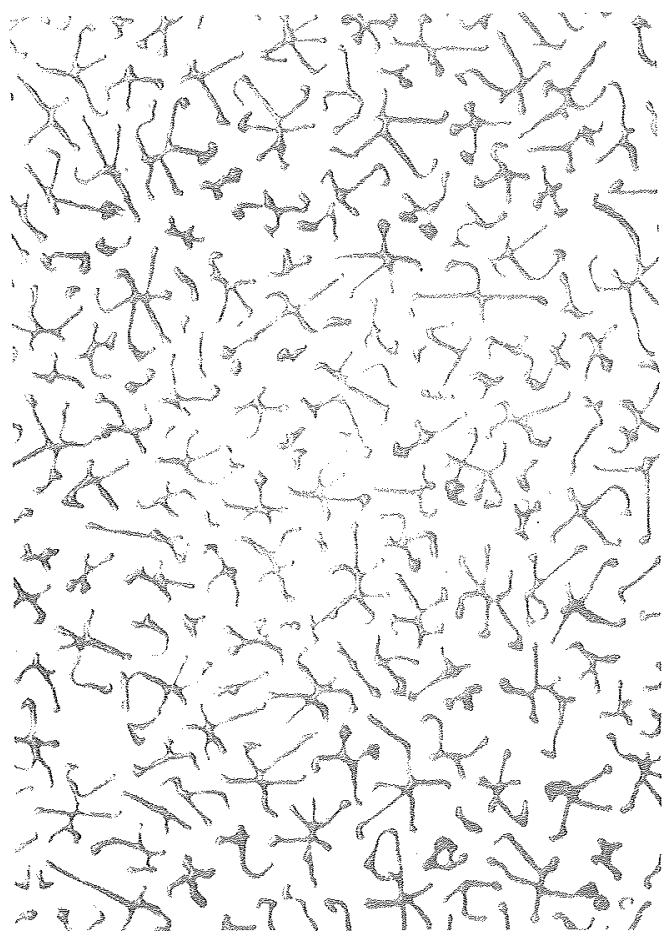

Fig. 61

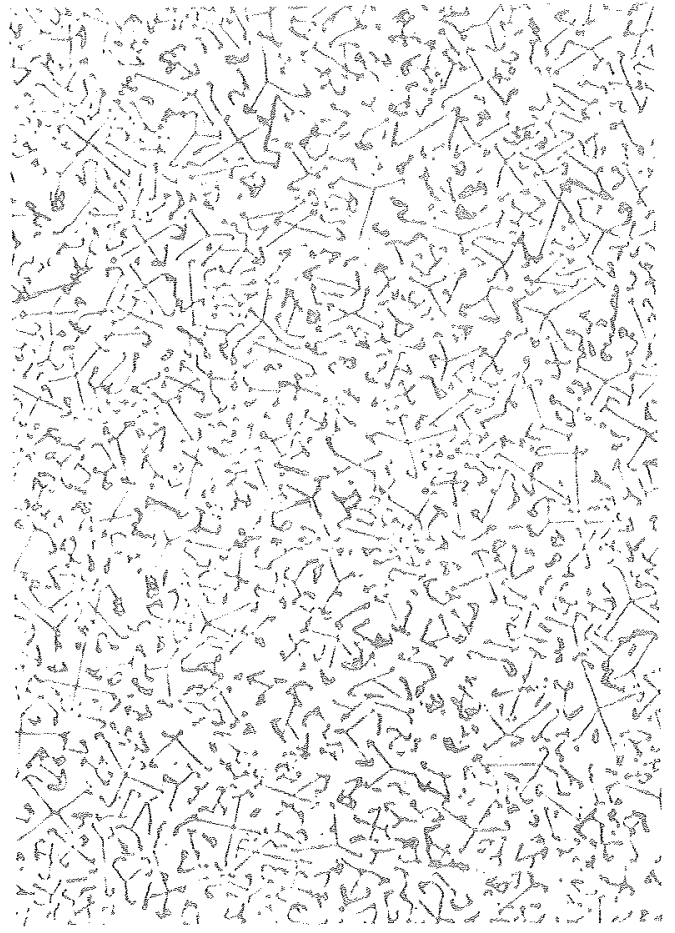

Hig. 6

XBB $7512 \cdots 9072$ 


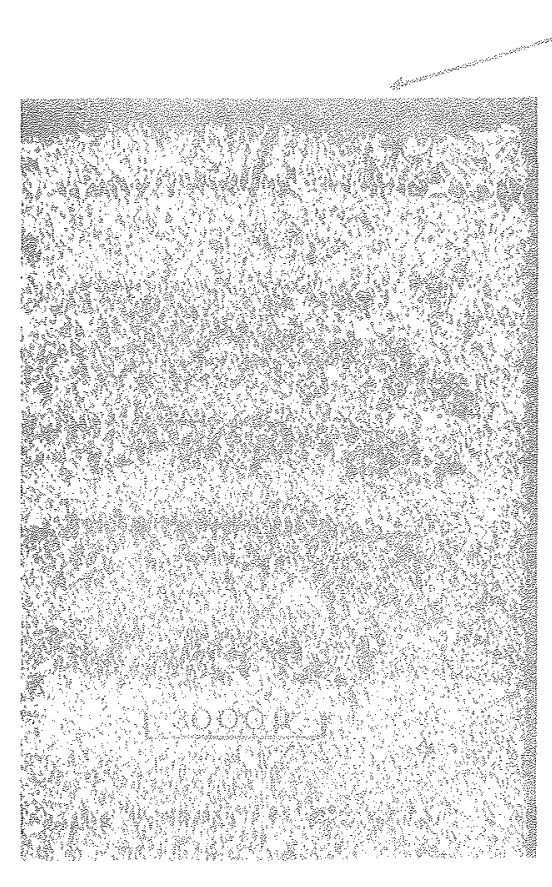

Wo. 79

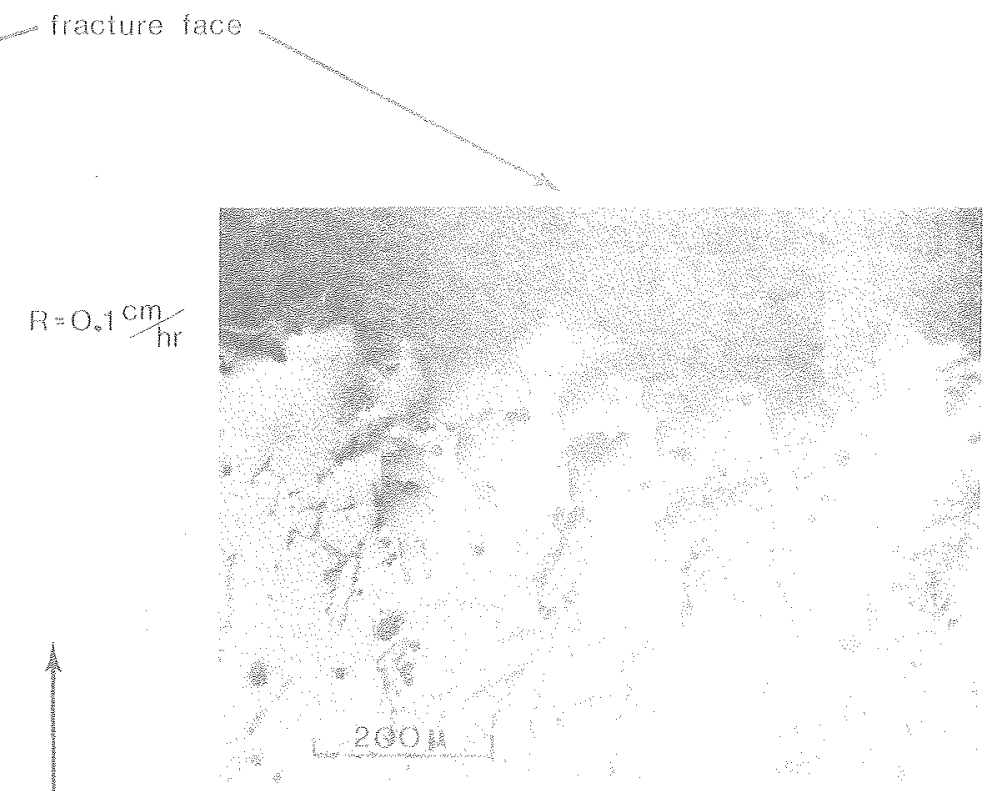

Fig. $7 b$

Growth Drection

Prenमा? taro
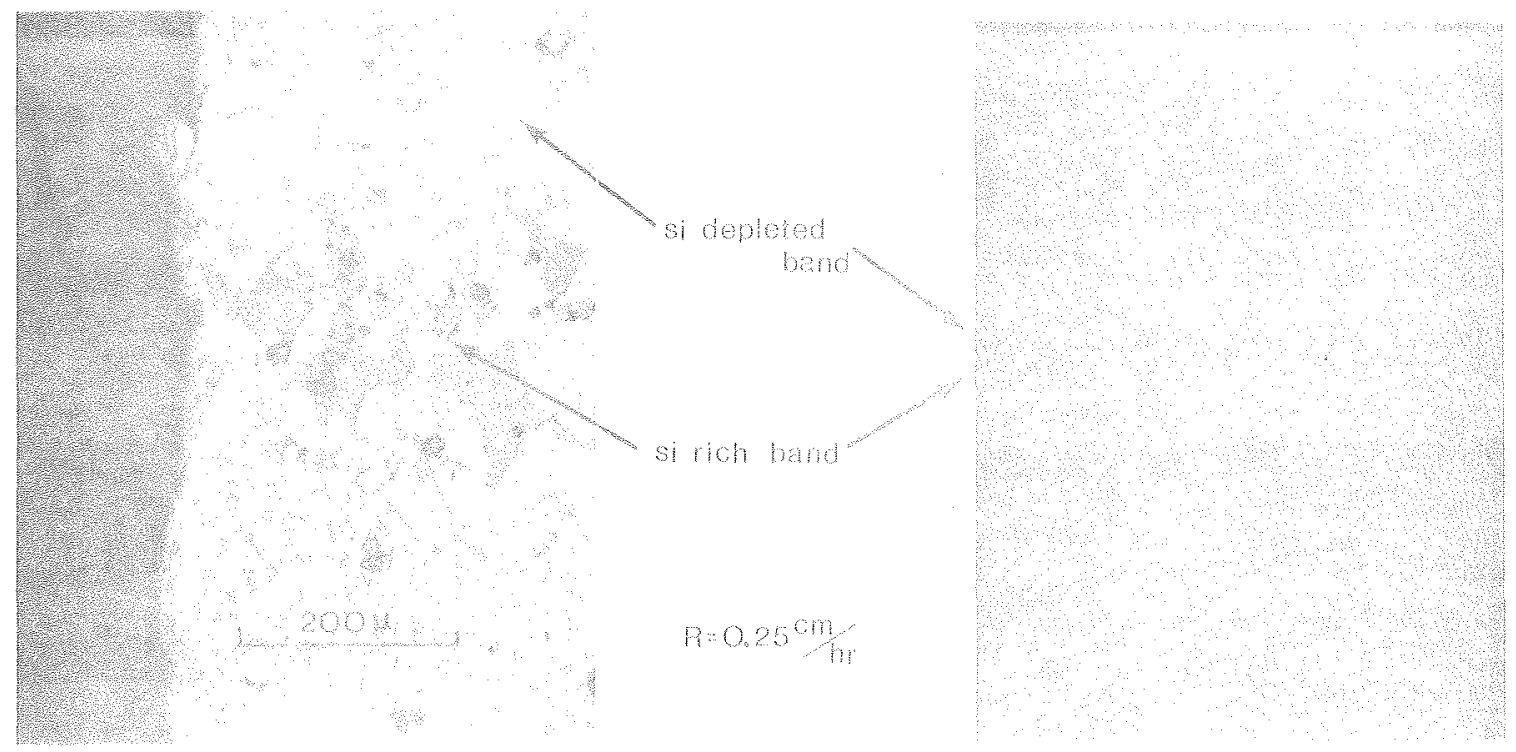

Fis. $\%$

सח 


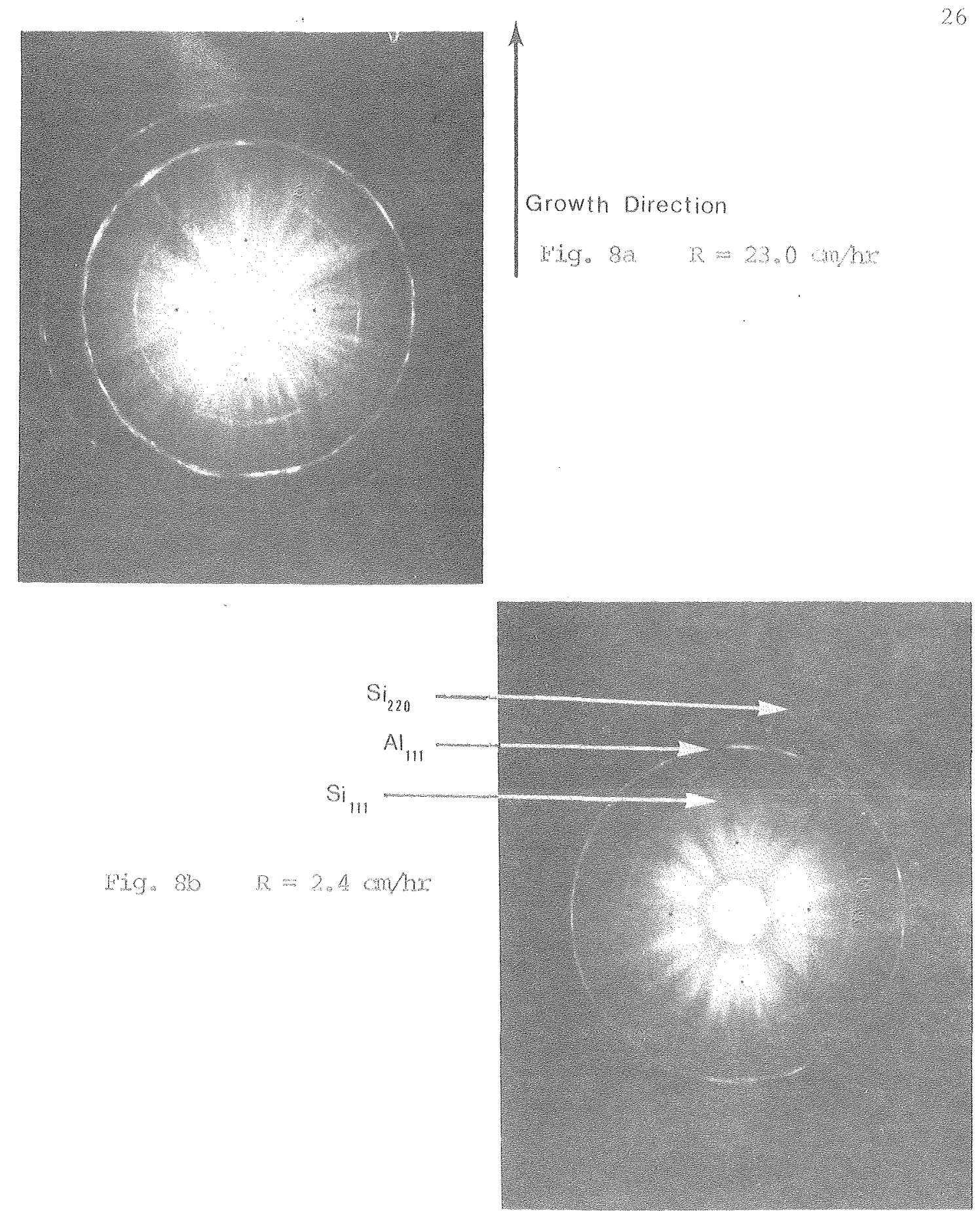

XBB $\quad 7512-9073$ 


\section{$04+4+74+030$}

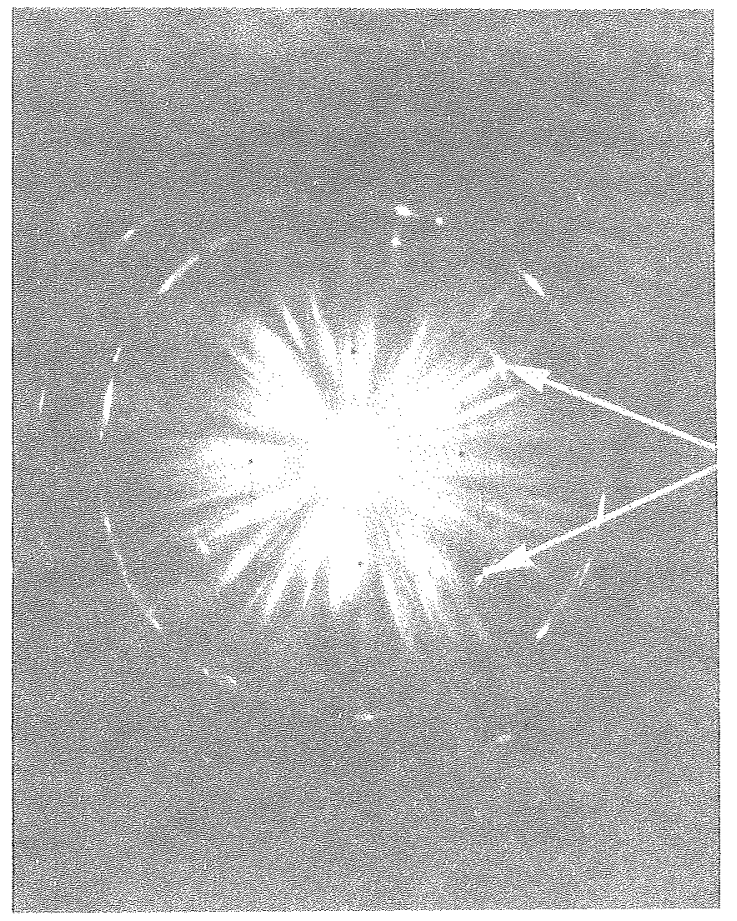

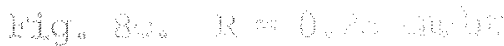

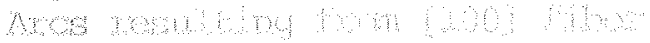

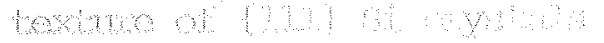

Arcs

Growh Droction

"19. का स $=0.9 \mathrm{~m} / \mathrm{m}$

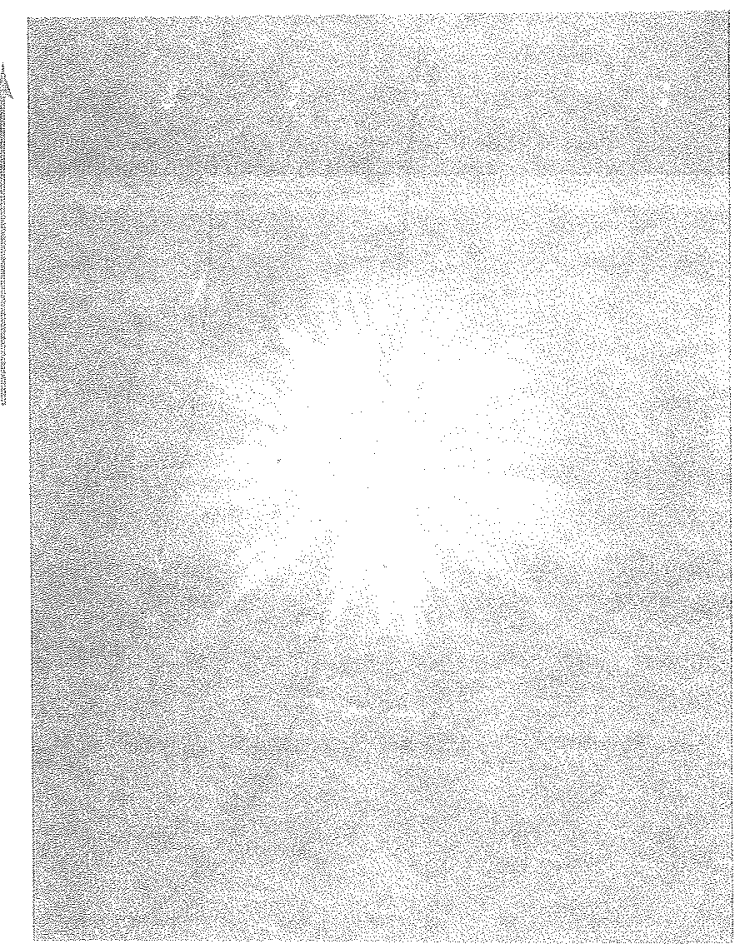

$831979 \% .90 \%$ 


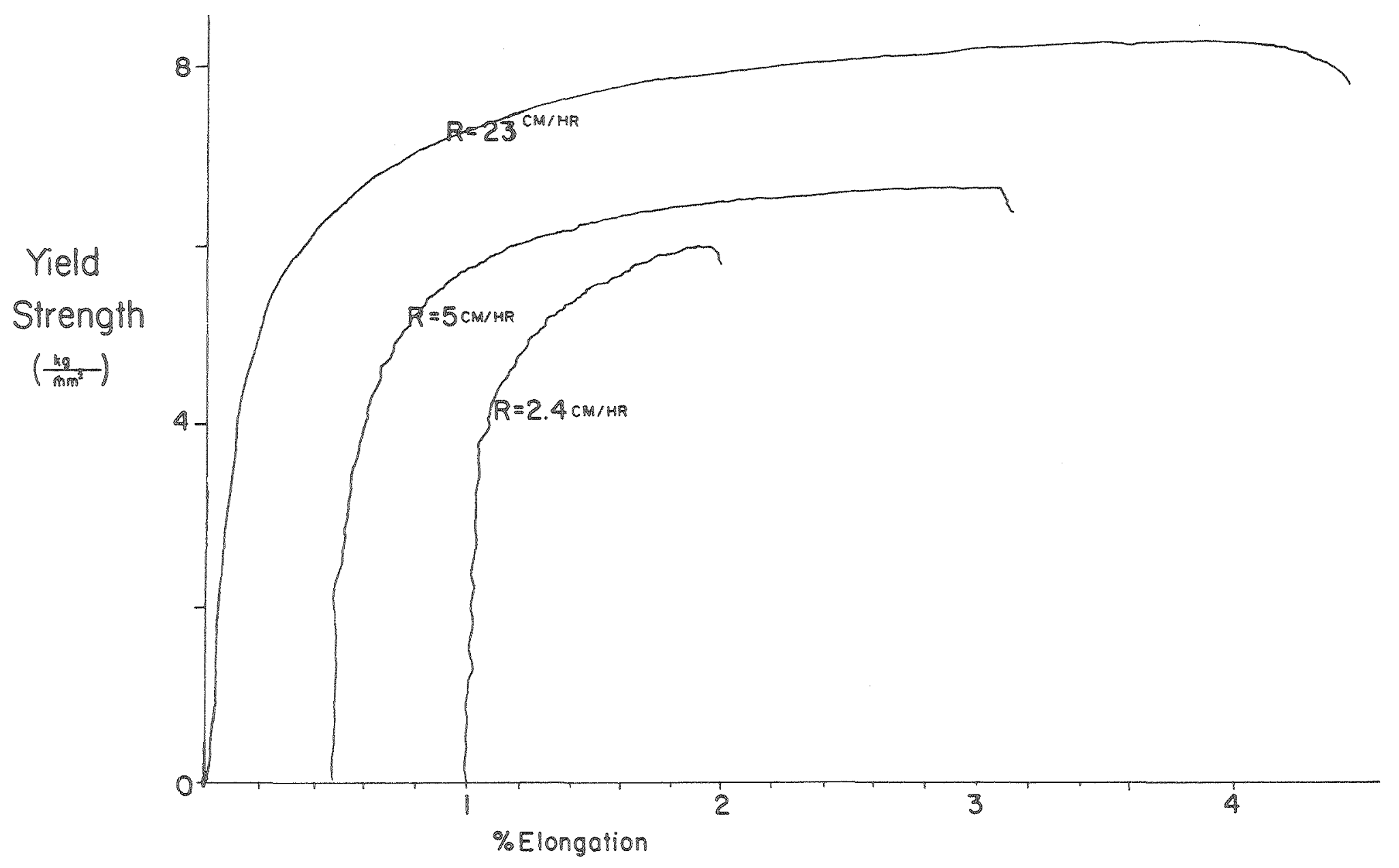

Fig. 9 (NOTE: Separate zero points taken for each growth rate.) 


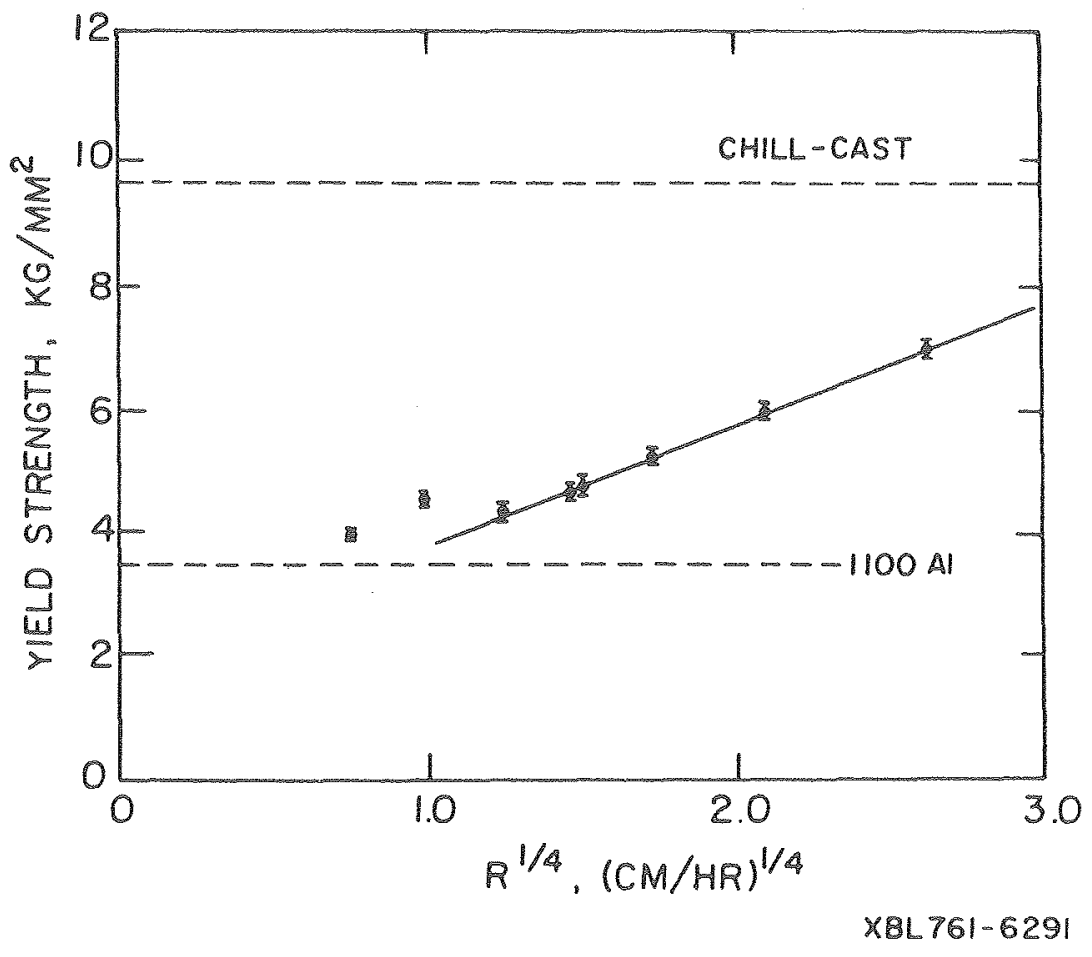

Eig. 10 

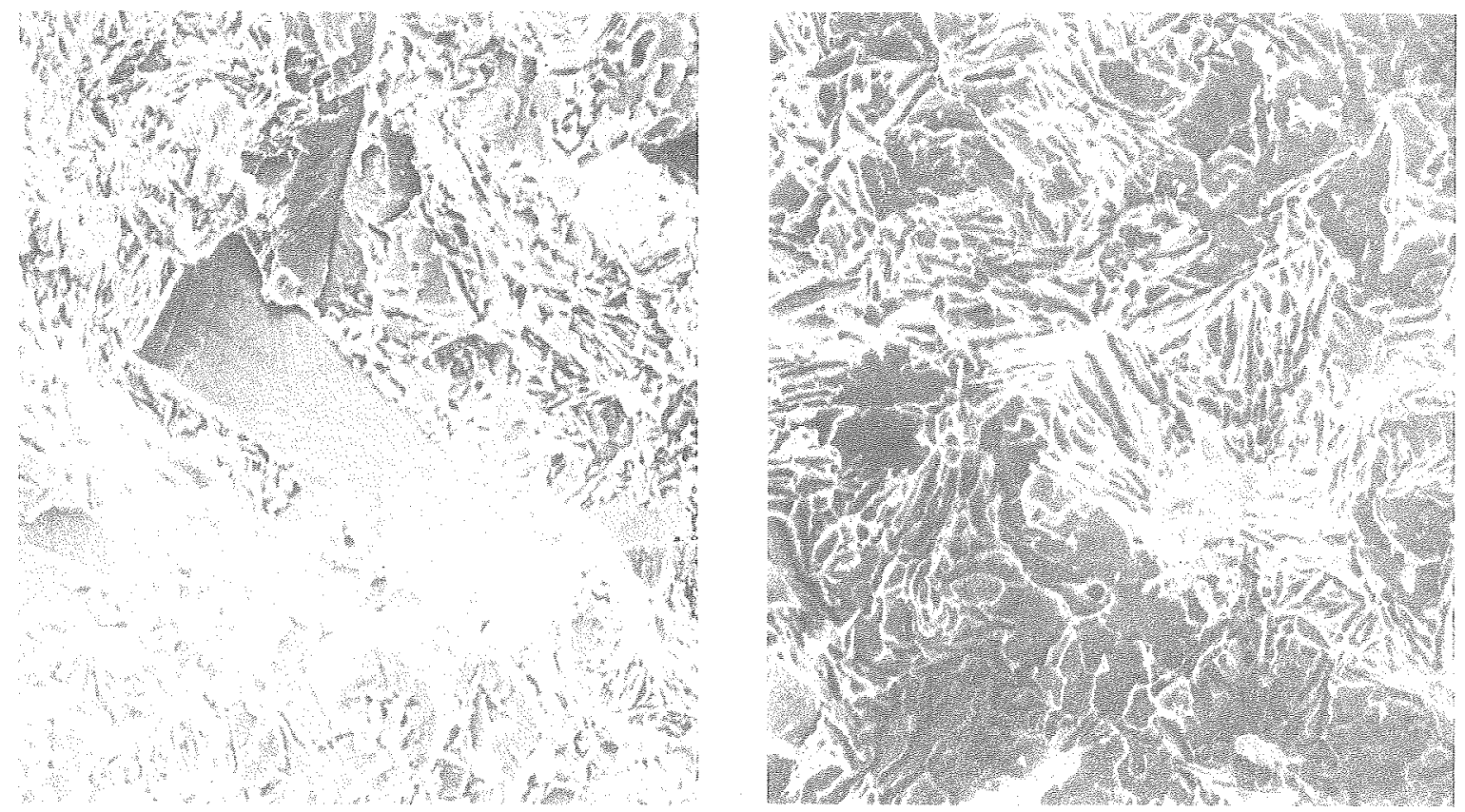

hig. Ina ( $\mathrm{R}=4.6 \mathrm{~cm} / \mathrm{hr})$

mig. $1 \mathrm{~b}(\mathrm{n}=23.0 \mathrm{~m} / \mathrm{ht})$
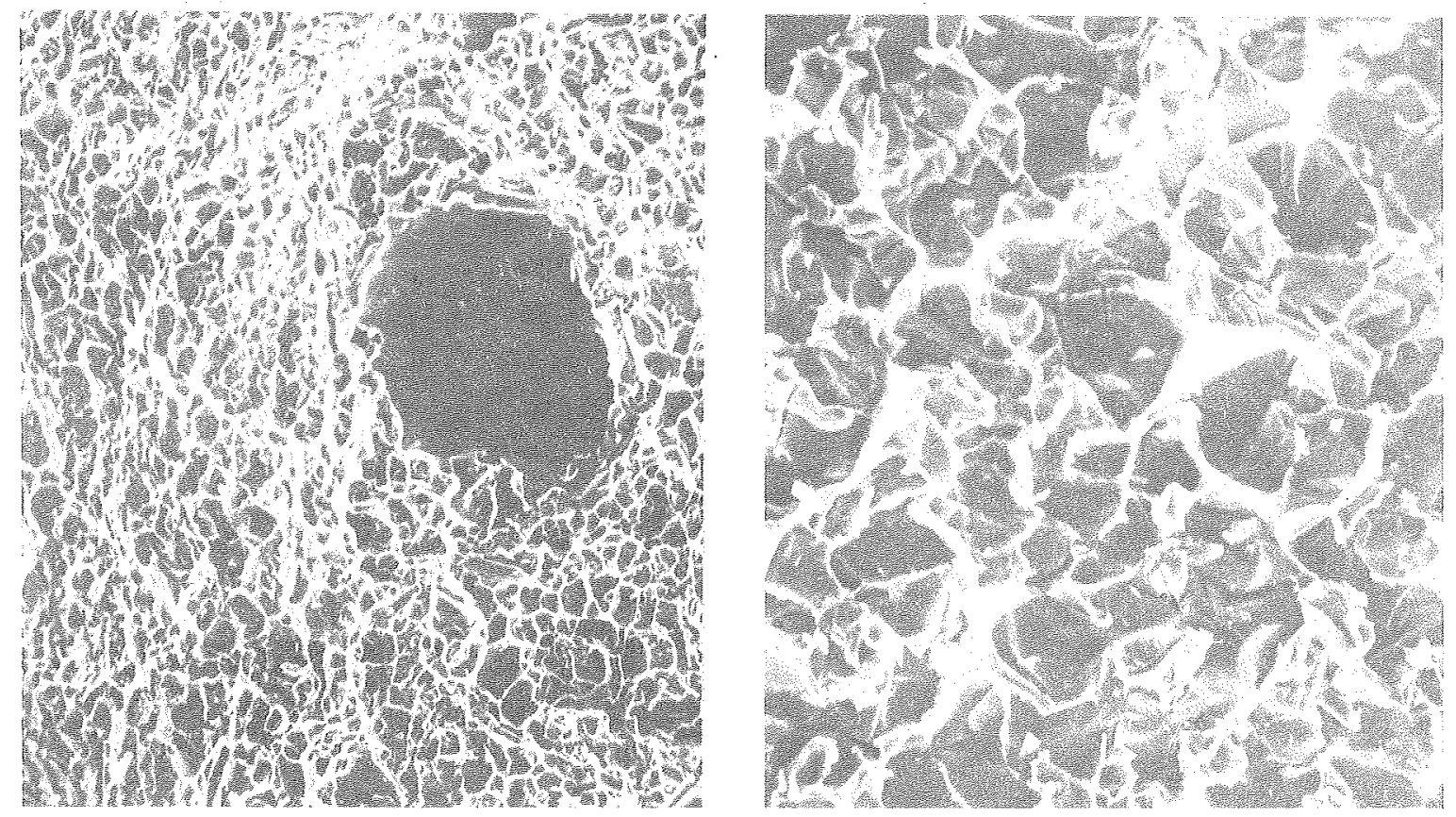

Fig. $11 \mathrm{c}(\mathrm{R}=.97 \mathrm{~m} / \mathrm{hr})$

Ho. $12 d$ ( $R=.097 \mathrm{~mm} / \mathrm{hr})$

$X B B \quad 7512 \cdots 9071$ 


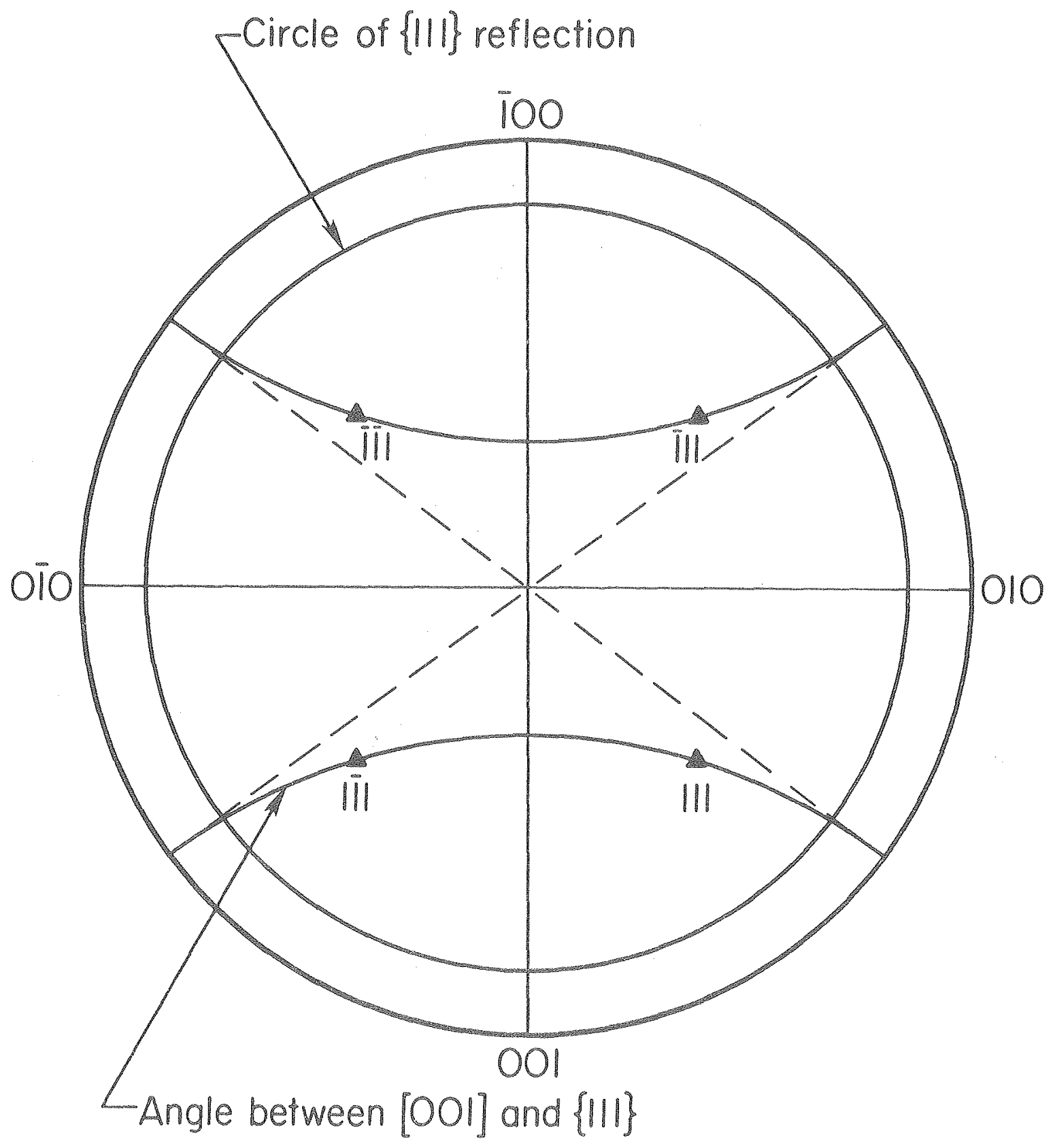

XBL 763.2445A

Fig. 12 


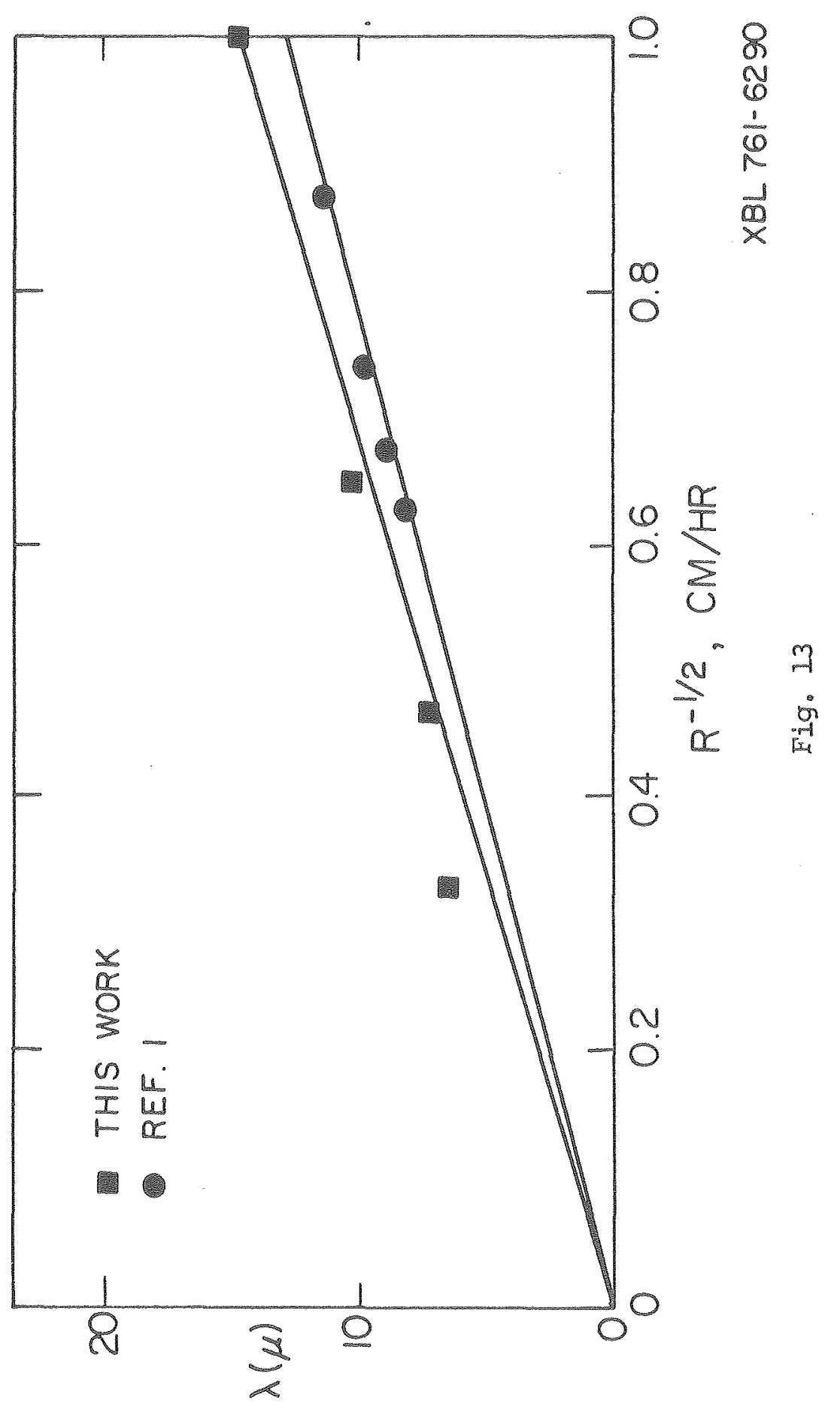


This report was done with support from the United States Energy Research and Development Administration. Any conclusions or opinions expressed in this report represent solely those of the author(s) and not necessarily those of The Regents of the University of California, the Lawrence Berkeley Laboratory or the United States Energy Research and Development Administration. 